\title{
Health Risk Communication and The Hazards of Portable Electricity Generator Use: A Study of Awareness and Knowledge of Carbon Monoxide Poisoning Among Resident Nigerian Public University Students
}

\author{
Allen Nnanwuba Adum \\ Department of Mass Communication, \\ Nnamdi Azikiwe University, Awka, \\ Anambra State, Nigeria \\ Emeka Odogwu \\ Department of Mass Communication, \\ Nnamdi Azikiwe University, Awka, \\ Anambra State, Nigeria \\ Kobimdi Umeh \\ Department of Mass Communication, \\ Nnamdi Azikiwe University, Awka, \\ Anambra State, Nigeria \\ Roseline Chioma Amete \\ Department of Mass Communication, \\ Nnamdi Azikiwe University, Awka, \\ Anambra State, Nigeria
}

\section{ABSTRACT}

The overall objective of the study was to determine Nigerian university students' awareness and exposure to label warnings on portable electric power generators; their level of comprehension of these label warnings; knowledge of carbon monoxide poisoning; and, preventive measures taken to avoid carbon monoxide poisoning. The survey research method was used for this study. Data was collected in Southeastern Nigeria among undergraduate students, by administering questionnaire to a sample of 400 students from four universities. The study found a high level of exposure to label warnings on house hold products but a minimal exposure to label warnings on portable electric power generating sets among these students. Variables like placement of the warnings, font sizes and religious inclination hindered exposure to the warnings and compliance to the warning message; awareness of carbon monoxide information was high and a greater number among the respondents got informed either through their families and friends or read about it; a relatively lower number got informed through the media. While these university students were aware of carbon monoxide poisoning, they were not properly informed of the different symptoms that are associated with the gas and the preventive measures that could prevent carbon monoxide poisoning. This suggests that carbon monoxide poisoning is not being taken seriously as a health hazard among people susceptible to poisoning.

Key words: Health risk communication, portable electricity generator use, carbon monoxide poisoning, label warnings

DOI: $10.7176 / \mathrm{JEES} / 9-6-14$

Publication date:June $30^{\text {th }} 2019$

\section{INTRODUCTION}

In the month of March, 2019, four siblings of the same family were found dead by their neighbors. According to coroner's report released by the police department, the cause of their death was inhalation of a poisonous gas called Carbon Monoxide. Further investigation carried out by the police showed that this gas came from the exhaust fumes of an electric power generating set placed very close to the family's window. These deaths and many others reported by the media probably occurred because owners and users of electric power generating sets apparently 
do not follow instructions/ warnings placed on both the bodies of these machines and in the manuals; to guide them on the proper way to operate these machines.

Each year in Britain and countries all over the world, approximately 50 people die and two hundred people suffer severe morbidity by carbon monoxide poisoning. This poisoning is caused by intentional harm, but most of it is accidental. Carbon monoxide (CO) is the most common cause of accidental poisoning, and according to one estimate, $\mathrm{CO}$ poisoning symptoms in as many as 25,000 people in the UK can be attributed to faulty gas appliances (Afolayan,Olajumoke,Amadasun\&Isesele,2014).

Carbon monoxide according to scholars is considered to be a major factor contaminating earth's atmosphere. The main sources producing this contamination are cars and machines using gasoline or diesel fuel and industrial processes using carbon compounds. These two alone are responsible for $80 \%$ of carbon monoxide being emitted to the earth atmosphere. These substances have a well-known toxic effect on human beings and its acute poisonous effects (including death). The United States Environmental Protection Agency explains that exposure to CO can reduce the oxygen-carrying capacity of the blood, and can result to the individual collapsing and losing consciousness and in extreme cases, death. In fact, CO may be responsible for more than one half of all fatal poisonings that are reported worldwide each year (National Safety Council, 1982; Cobb \& Etzel, 1991; Mathieu, Mathieu-Nolf, Wattel, 1996).

CO poisoning deaths specifically associated with generators have been increasing annually. In 1999, generators were associated with $7(6 \%)$ of the total yearly estimated CO poisoning deaths for that year. In 2000, 2001 and 2002, they were associated with 19 (14\%), $22(17 \%)$ and $46(24 \%)$ deaths out of the total estimates for each of those years (Consumer Product Safety Commission, 2007).

Due to the increase in the death rate associated with CO, the U.S. Consumer Product Safety Commission (CPSC) on $4^{\text {th }}$ of January 2007, voted unanimously, requiring manufacturers of portable generators to warn consumers of carbon monoxide (CO) hazards through a new "Danger" label. The label states that, "Using a generator indoors CAN KILL YOU IN MINUTES". Manufacturers will be required to place the "Danger" label on all new generators and the generators' packaging. The label warns consumers that a "generator's exhaust contains carbon monoxide, a poison that cannot be seen and has no odour, and that generators should never be used inside homes or garages, even if doors and windows are open". This decision was pioneered because of the level of accidental and non-fire related carbon monoxide death linked to consumer product.

\section{A DANGER}

Using a generator indoors CAN KILL YOU IN MINUTES. Generator exhaust contains carbon monoxide. This is a poison you cannot see or smell.

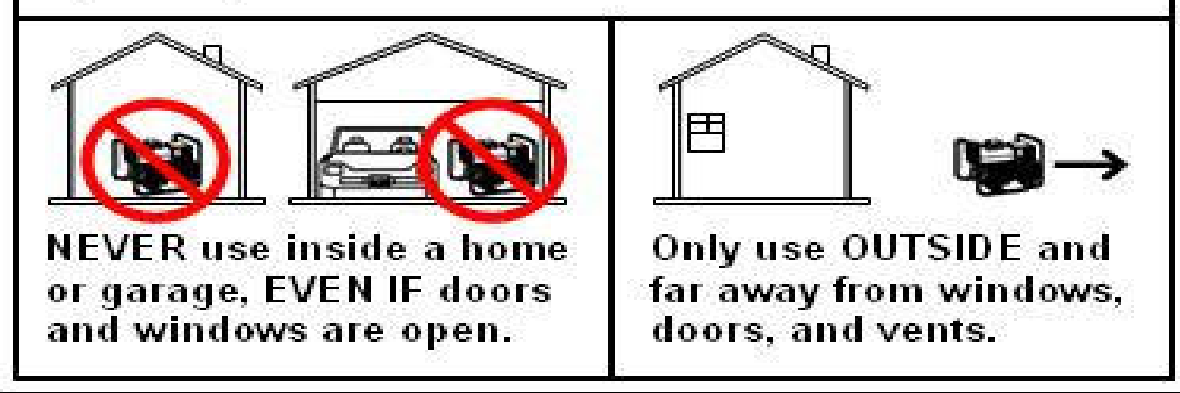

Figure. 1: A typical example of $\mathrm{CO}$ warnings placed on generators.

According to CPSC (2007), a well-designed warning label is believed to inform the consumer of the CO hazard associated with generators and how to avoid the hazard while using the generator. Label warning and instructions placed in a prominent position on the generator is expected to inform and reinforce this information each time the consumer uses the generator. For example, the proposed label jogs the consumers memory that generator exhaust 
contains $\mathrm{CO}$, which cannot be seen or perceived, and can quickly kill. The label also clarifies that a generator should only be used outside and far away from windows and vents, and should not be used inside a home or garage. This information is therefore very important since some consumers have apparently been aware that a CO hazard was associated with generators, but believed that they could avoid the hazard by running the generator in a garage with the door open or outside the house, and did not understand that it was necessary to place it away from open windows and vents.

Africa is one continent where carbon monoxide poisoning is on the rise and most times they go unmonitored. Nigeria on the otherhand is one of the largest populated West African countries and almost on a daily basis, there are reports of incidents related to $\mathrm{CO}$ poisoning. These incidents could be linked to the epileptic situation regarding power supply, leading to the increase in the purchase and use of portable electricity generators which is a major source of $\mathrm{CO}$.

According to a research carried out by Global Business Intelligence (2016), generator importation and domestic sales in Nigeria recorded a peak of N65.476 billion ( $\$ 411.8$ million) in 2008 . These figures have continued to increase with a subsequent study revealing an estimated N1.3 trillion (approximately $\$ 9.6$ billion) spent between 2009 and 2012 purchasing generators. Nigeria currently ranks as the largest importer of generators in the world. With only about $48 \%$ of the inhabitants in Nigeria enjoying access to electricity, it is therefore no surprise that such large sums are spent purchasing generators. The typical portable generator ranges from the cheap and lowly "I better pass my neighbor" to the high end noiseless series. To most Nigerians, "I better pass my neighbor" is a life saver. Affordable and cheap to maintain, there are very few homes in the cities, towns and even villages where the robust little contraption has not found a place.

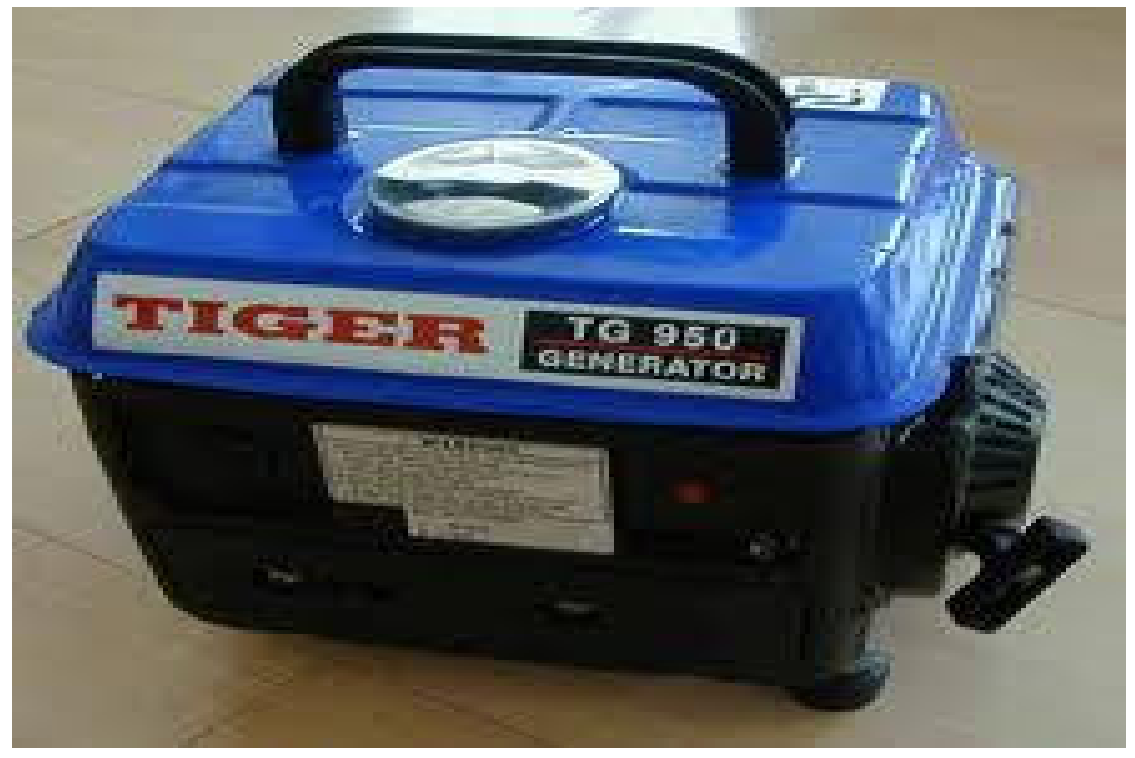

Figure.2: A Chinese made generator (I better pass my Neighbor)

As Nigeria holds the record of the highest user of standby generator, so the country holds the record of the highest death associated with $\mathrm{CO}$ poisoning. Figure 3 below shows a family of 9 from Emekuku in Imo State, who lost their lives to fumes from generator. Investigation into their death, showed that the family forgot to turn off their generator and fell asleep while inhaling the poisonous gas. 


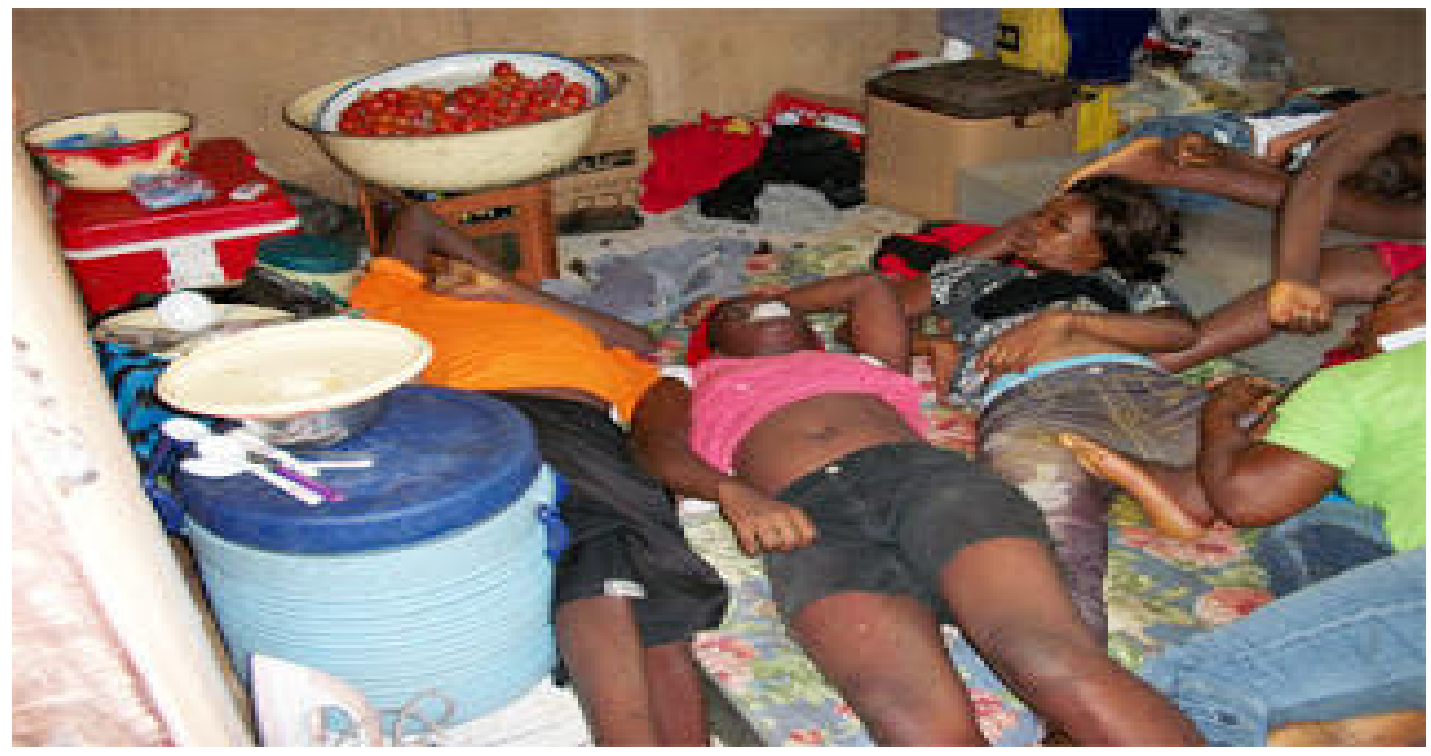

Source: Linda Ikeji. Figure.3: Family of 9 poisoned through inhalation of CO.

Over and over again, medical professionals have raised alarm on the increase in number of deaths related to $\mathrm{CO}$ poisoning in Nigeria. On the $4^{\text {th }}$ of October, 2013, Dr Olatunyi Ekemode warned Nigerians that the fume from generators was a silent killer. According to him "generator fumes can be deadly when inhaled, as CO replaces oxygen in the body tissues. When Oxygen is displaced in the body, it prevents blood from carrying out its functions, including transporting oxygen around the body. A pathologist, Dr Adekunle Soyemi, advised owners of these portable generators "never to leave a generator too close to the house, unless there is enough ventilation to prevent painless death".

Carbon monoxide poisoning is often very difficult to detect and in most cases leads to serious health problem before it can be noticed. There are two main reasons why CO poisoning goes unnoticed. Firstly, there is generally little awareness of carbon monoxide poisoning among the general public and the medical profession. Secondly, the signs and symptoms associated with carbon monoxide poisoning are not easy to detect as they often mimic many other conditions. To overcome this deadly killer requires improved awareness among the public of the risks and dangers of carbon monoxide poisoning and increased vigilance on the part of healthcare professionals in its detection.

This paper therefore investigates resident Nigerian students' awareness and exposure to CO poisoning and label warnings about it, as well as the preventive measures taken to avoid carbon monoxide poisoning.

\section{AIMS OF STUDY}

The main aim of this study was to determineresident Nigerian public university students' level of awareness and exposure to label warnings regarding carbon monoxide poisoning that are placed on electric power generating sets as well as preventive action taken to avoid possible carbon monoxide poisoning. The study sought answers to the following questions:

1. What is the level ofresident Nigerian public university students' awareness and exposure to carbon monoxide label warnings on portable electricity generators?

2. To what extent do they comprehend these label warnings?

3. How much do they know of carbon monoxide and the risk of exposure to it?

4. Can these students identify symptoms of $\mathrm{CO}$ poisoning? 
5. Dothese university students take preventive action to mitigate carbon monoxide poisoning?

\section{LITERATURE REVIEW}

Risk communication according to the World Health Organization is any purposeful exchange of information about risks between interested parties (WHO, 2001). In recent times, the issues in risk communication have been with regards to policy making; that there was an emphasis on 'public misperceptions' with a tendency to treat all deviations from expert estimates as products of ignorance or stupidity (Bennett ,1999). Therefore the need to inform the public of dangers that can erupt from the misuse of products has lead manufacturers to properly inform their consumers of these hazards through proper product labeling, instruction manuals etc. in order to bring risk to its barest minimum.

\subsection{Communicating Health Risk of Consumer Products}

Communicating about risk cannot be reduced to a simple formula. There's a wide range of potential hazards that can pose risks to one's health. These health risks can vary in severity, certainty, probability and complexity. The communication of these issues takes place in a complex environment with many stakeholders and sources of information, which vary in their reliability and importance. Risk communication therefore involves a combination of complex processes, including scientific appraisal and characterization of risk, application of knowledge concerning people's values, perception and management of risk, and ongoing partnership and information exchange (Council of Canadian Academies, 2015).

Risk is defined in a number of ways. Rohrmann (2008) defined risk as the possibility of physical and or social and or financial harm, detriment or loss due to a hazard within a particular time frame. The international Risk Governance Council (IRGC) defined risk as an uncertain (generally adverse) consequence of an event or activity with respect to something that humans value, but also explains that risk can have positive or negative consequences depending on the values that individuals or groups associate with them (IRGC,2008).

Risks to health and risks from health products are a subset of risks. Health Canada (2000) formally defines health risk as a measure of both the harm to human health that results from being exposed to a hazardous agent, together with the likelihood that the harm will occur.Since characterizing, managing, and communicating potential risks varies greatly depending on the agent, it is important to clearly define the nature of the hazard involved (IRGC, 2005). Health risk communication is part of the responsibilities of several regulatory agencies around the world.Different agencies define health risk communication in different ways, but each definition includes the concept of exchange of information to improve or maintain health (Health Canada, 2006; FDA, 2009; EMA, 2010; MHRA, 2010; en Health, 2012).

Risk communication has become a very important part of our lives. We are exposed to information about risk on a daily basis. These messages are all around us and often appear to be omnipresent; cars beep when we do not fasten our seat belts, cigarette packets show graphic pictures to warn us of cancer, generator labels warns of possible exposure to carbon monoxide.

Communicating health risks entails several stages, including analysis of a potential threat, understanding the perceptions of relevant populations, and disseminating the message in an appropriate manner (Fischhoff \& Kadvany, 2011). This process allows a risk or hazard to be properly communicated based on evidence and in a manner that ensures that those most likely to be affected will receive the message and understand it in order to take the desired action. It is important to note, that, risk communication requires the identification of the most important facts and information related to a risk, often from large amounts of technical information by experts in health-related fields (Fischhoff \& Kadvany, 2011). Communicating information about product health risks involves medical professionals or specialist conveying information in a manner that is comprehensible to various populations with different demographic background. 


\subsection{The Essence of Industrial Label Warning}

According to WHO,(2004), product labels are an essential part of hazard communication, providing the user with information about the chemical nature of the hazard, the identity of the substance, advice in case of exposure, instructions for storage and use, and cautions or warnings.

While there are many ways in which a manufacturer can warn and inform users and owners of different products of the harm they put themselves if they are not properly operating these products, warning labels attached to products or inscribed on product manuals is a traditional means said to be one of the most effective method of fulfilling this duty.

Warnings are a form of safety communication, intended to inform persons at risk about hazards and minimize undesirable consequences of interactions with circumstances that may result in illness, injury, or property damage ( Wogalter\& Dingus, 1999; Wogalter \& Laughery, 2006). According to Wogalter and Laughery (2006), warnings have several established purposes. First, warnings are a means for conveying important safety related information to users, allowing them to make well-informed decisions regarding product usage. Second, warnings attempt to minimize injuries, illnesses, and property damage associated with product usage. In addition, these authors suggest that a warning can act as a reminder, cuing information that is stored in long-term memory and prompting awareness of a particular hazard.

Effectively designed warnings can reduce or eliminate unsafe acts associated with hazardous circumstances (Wogalter, Godfrey, Fontanelle, Desaulniers, Rothstein, \& Laughery, 1987). For instance, effective warnings should include information about a potential hazard, its consequences, and instructions for avoiding risk (Wogalter \& Laughery, 2006), be placed physically and temporally close to the hazard (Frantz \& Rhodes, 1993; Wogalter, Barlow, \& Murphy, 1995), and from a source that individuals perceive as credible (Wogalter, Kalsher, \& Rashid, 1999).

ANSI (2002) is a standard for warnings that says that each warning should include a signal word panel along with a message panel, a symbol, or both, when appropriate. The signal word panel for hazardous product or environments includes the signal word (DANGER, WARNING, or CAUTION), its corresponding background color, and the safety alert symbol (ANSI, 2002). The signal word and background color redundantly code the level of hazard. The message panel should communicate the nature of the hazard, the consequences of not avoiding the hazard, and how to avoid the hazard. Symbols may be used in conjunction with or in lieu of the word message in the message panel, according to the Z535.4 standard's 2002 revision (Smith, 2010).In short, they are meant to alert people of a hazard in a short amount of time. Though legally, warning labels holds no responsibility for changing human behaviour (Robinson, 2009), they inform users of the product of appropriate behaviours to undertake in order to avoid danger, injury or hazard.

\subsection{The Issues of Comprehensibility of Label Warnings}

There are considerable philosophical differences on the approach to providing information to consumers. Labeling based on the likelihood of injury (i.e. risk communication) is considered to be an effective approach in this respect by some consumer labeling systems, whilst others take account of the "right to know" principle in providing information to consumers which is solely based on the product's hazards(Globally harmonized system of classification and labeling of chemicals, GHS) (2009).

Consumer education is more difficult and less efficient than education for other audiences. Providing sufficient information to consumers in the simplest and most easily understandable terms presents a considerable challenge. The issue of comprehensibility is of particular importance for the target audience, since consumers may rely on label information.

Comprehensibility refers to the ability of an individual reading a label or warning to understand the information sufficiently in order take the desired action. Comprehensibility is different from readability because the latter is simply a measure of the grade level of the written material while the former is a measure of how well the receiver of the information understood it. A warning about incompatible chemicals may be written at the correct reading level for a specific audience but may do such a poor job at explaining the concept of incompatibility that the warning isn't understood by most of the intended audience. Two experiments involving warning labels on household products (Godfrey and Laughery, 1993) indicated that subjects are able to discriminate among products 
based on overall hazard. The more hazardous they perceived a product; the more likely it was they would look for a warning.

Appropriate labeling is essential, but it is ineffective if the print is too small to read easily or covered by stains, or if the label has been torn away. The effectiveness of labels also depends on how well the user understands the message. Words are usually clear and unambiguous to those who know the language well, but incomprehensible to those who do not understand the language or who cannot read (i.e. people who are illiterate or have a low level of literacy, who have poor eyesight, or are small children). Therefore, factors which can hinder exposure and comprehensibility of label warnings are discussed below.

\subsubsection{Use of Symbols and Pictograms on Label Warnings}

Understandably, standards for warning labels exist to create an ideal universal language of risk that protects both the manufacturer and the consumer, and research shows that pictorials greatly affect human perception of risk (Rodriguez \& Asoro, 2012; Schneider, Gadinger \& Fischer, 2012; Wogalter, Conzola \& Smith-Jackson, 2002). The presence of pictorials has also been shown to enhance memory of a warning (Young \&Wogalter, 1988).

A warning must first be legible before it can be comprehended. Legibility refers to the degree of initial clarity of the warning. Thus, legibility is based on size of the pictorial and is affected by the distance from which it will be viewed. Environmental conditions such as sunlight, humidity, temperature, or the presence of certain chemical substances, can erode the legibility of a warning overtime (Wogalter, Conzola \& Smith-Jackson, 2002). Pictorials are most effective when they communicate simple, concrete concepts, and are less effective at representing abstract concepts (Murray, Maguo, Glover \& Wolgater, 1998).

Records show that there are more than 100 languages that are read and spoken all over the world. It is therefore very important to develop a method that will effectively communicate safety information to readers of products label warnings and instructions. Adequate safety communications that are not effectively communicated to expected users may be considered problematic. English Language is a considered as the universal accepted language, the law therefore does not require labels in a language other than English and providing labels in other languages may be risky when the product is going to be used internationally.

In the U.S., the Federal Appellate Court set forth two essential characteristics of a legally adequate warning:

1. It must be in such a form that it could reasonably be expected to catch the attention of a reasonably prudent man in the circumstances of its use

2. The content of the warning must be of such a nature as to be comprehensible to the average user and to convey a fair indication of the nature and extent of the danger to the mind of a reasonably prudent person (Legal professionals, 2008).

An important function of pictorials and symbols is to facilitate warning comprehension (Dewar, 1999). Over the years, there has been a great interest in depicting critical safety and health information as briefly as possible for immediate response by individuals in dangerous situations. The focus has been to avoid the numerous shortcomings of written language particularly the length of time it takes to read a warning and the proximity the reader must have with the information in order to see it. The need for shortened label information is deemed necessary because humans are considered impatient beings; therefore long essays on health information might not attract them to flip through. For instance, the leaflets placed inside the boxes the products are being sold in. As such, pictorials can be helpful by attracting the individuals to expose themselves to the message.

Because of their relatively universal information transmission potential, pictorials have been suggested as common means of safety communication across heterogeneous groups of users (Brelsford, Wogalter, and Scoggins, 1994). Several studies found that easy pictorials were comprehended better than difficult pictorials, although the latter showed the most dramatic increase in understandability after training.

Young and Wogalter (1990) found that better comprehension and recall of warnings in manuals for a gas-powered electric generator and a natural-gas oven were found with larger-print, the use of color, and the inclusion of symbols. Furthermore, Young, Wogalter, Laughery, Magurno, and Lovvoll (1995) and Kalsher, Wogalter, \& Racicot, (1996) found that individuals prefer warnings that include a pictorial symbol to warnings that do not include pictorials. 


\subsubsection{Type Fonts and Type Sizes of Label Warning}

Bold type is preferred because of its greater contrast with most backgrounds; however the stroke width must not be so wide that features of individual letters are obscured (Sanders \& McCormick, 1993). Adding color to a warning can increase its ability to attract attention (Gill, Barbera \& Precht, 1987) provided that the warning color is distinguishable from background and surrounding colors.

Kline, Braun, Peterson \& Silver (1993) found that colored warning labels were perceived as more readable and hazardous than achromatic labels. Warnings printed in red (compared to black) led to improved noticeability (Braun, Sansing, Kennedy \& Silver, 1994; Young, 1991).

Looking at pesticide labeling, Silver, Kline and Braun (1994) obtained different results from their earlier work with prescription drugs. The variables used were the same: font type, point size contrast between the signal word and the main body of the warning (signal word-text size difference), and point size of the signal word. College students rated 36 insecticide labels that contained a warning which varied across all levels of the three variables. Results showed that Century Schoolbook was perceived as more readable than Bookman or Helvetica. Moreover, greater perceived readability was obtained when there was no difference between the point sizes of the signal word and the body of the warning. Perceived readability and perceived hazardousness decreased as the signal word-text size difference increased. There was greater perceived readability and perceived hazardousness when the signal word was printed in 14-point type than in 12- or 10- point types.

\subsubsection{Placement and Layout of Warning Information}

One of the key variables on warning effectiveness is where the information is placed. This includes placement of information within a label as well as the physical placement of a warning sign in proximity to the hazard the warning describes.Manufacturers often place warnings both within product manuals and on the products themselves. Since space is often limited on the products themselves, some warnings are only placed within the products manual (Mehlenbacher, Wogalter, \& Laughery, 2002). However, some research suggests that many users do not read owner's manuals and, therefore, may not be exposed to information about hazards (Rettig, 1991; Schriver, 1997).

The proper placement of a warning depends on the nature of the task being performed as well as the task environment. A well-designed warning will be of little use if the user does not encounter it in the task environment. For instance the placement of a warning on a product will either increase or decrease the likelihood that it is noticed and comprehended. Warnings are most effective when they are presented proximate (in time and space) to the hazard. Frantz, Rhoades, Young \& Schiller, (2000) found that $98 \%$ of participants noticed a warning that was located on the physical object associated with the task. The placement of warnings included with product instructions has been shown to influence their effectiveness.

The amount of visual clutter in the vicinity of a warning significantly influences warning detection times (Godfrey, Laughery, Young, Laughery, Vaubel \& Horn, 1991; Wogalter, Kalsher \&Racicot 1993). Godfrey et al. found that warnings placed on the front label of a bottle printed horizontally were found more quickly than any other position. One possible way of reducing visual clutter on product labels is to increase the surface area of the label by using extended tags (which alters the layout of the warning).

In tests on the effectiveness of three different warning label designs for a portable electric heater, researchers Gill, Barbera, and Precht (1993) found that the design requiring the user to interact with the label in order to use the heater was more effective in attracting the user's attention than a traditional label or a color-coded "ski-pass" label attached near the male end of the electric cord. However, none of them were effective in mediating safe user behavior.

Wogalter et al. (1995) found that compliance was greater when warnings were placed on the product itself compared to on the product box or manual; indeed it was the only way to alert more expert users. Frantz and Rhoades (1993) suggested that compliance was greater when warnings were placed so they interfered with the task compared to when the warnings were merely placed on an object. These findings suggest that placement of a warning intended as a reminder in a conspicuous location on a product itself maynot only increase the likelihood that the safety related information to which one has been exposed is cued and then recalled, but also encourage compliance. 
A paradigm was developed to examine the effectiveness of warnings in a laboratory task (Wogalter, Fontenelle, and Laughery, 1993). Compliance (use of mask and gloves) was affected by the inclusion of the warning as well as by its location. Greatest compliance occurred when the warning was placed prior to the instructions. The addition of a printed statement placed before the instructions (with warning at the end) to read through the instructions before beginning produced intermediate compliance that was not significantly different from the warning beginning and end conditions. Observation revealed that when the warning message was at the end of the instructions subjects complied only when they saw the warning message before starting the task. These results indicate that if warnings are placed in front of instructions the consumer is more likely to read and comply.

FMC Corporation (1985), as part of their safety program, emphasized the appropriate placement of safety signs and labels to reduce the occurrence of accidents. Frantz (1992) found that contrary to current, recommended practice, substantially more subjects read and complied with warnings and instructions that appeared in the directions for use rather than the "precautions" section. On average, moving an instruction from the precautions into the directions increased the reading rate from $37 \%$ to $89 \%$ and increased the compliance rate from $48 \%$ to $83 \%$.

\subsection{Carbon Monoxide Poisoning as a Health Issue}

Carbon Monoxide (CO), also referred to as Carbonous Oxide, is a colourless, odourless, and tasteless gas that is slightly lighter than air. Exposure to high levels of carbon monoxide is extremely toxic to humans and animals. According to Encyclopaedia of the Earth, Carbon monoxide consists of one carbon atom and one oxygenatom. It is the simplest member of the class of inorganic compounds known as oxocarbons which includes carbon dioxide $\left(\mathrm{CO}_{2}\right)$, carbon suboxide $\left(\mathrm{C}_{3} \mathrm{O}_{2}\right)$, mellitic anhydride $\left(\mathrm{C}_{12} \mathrm{O}_{9}\right)$ and many others. When combined with a metal (i.e. an organometallic complex), the carbon monoxide is a ligand called carbonyl: for example, in nickel carbonyl with the formula $\mathrm{Ni}(\mathrm{CO})_{4}$

The deadly effect of carbon monoxide was known as long ago as Greek and Roman times, when the gas was used for executions. In 1857 Claude Bernard postulated that its noxious effect was caused by reversible displacement of oxygen from haemoglobin to form carboxyhaemoglobin. $\mathrm{CO}$ is called the silent killer because people do not know it is in the air. The gas is colourless and odourless. According to a report by Voice of America (2013), CO decreases the ability of the blood to carry oxygen to body issues. It does this by linking with the bloods. When the gas links with the blood is no longer able to carry oxygen to the tissues that need it.

Carbon monoxide poisoning is a major public health problem and may be responsible for a significant percentage of all poisoning-related deaths. (National Safety council, 1982; Cobb \& Etze, 1991; Mathieu et al., 1996) all agree that CO may be responsible for more than one-half of all fatal poisonings that are reported worldwide each year. $\mathrm{CO}$ can be inhaled when a person is outdoor or indoor. Outdoors, concentration of $\mathrm{CO}$ are highest near traffic intersections, in congested traffic, near exhaust gases from internal combustion engines and from industrial combustion sources and in poorly ventilated areas such as parking garages and tunnels. Indoors,

Medical experts say carbon monoxide affects people differently. For example, a small child will experience health problems or die much quicker than an adult will. An older adult with health problems may suffer the effects of carbon monoxide more quickly than a younger person with no health problems while people with heart diseases may suffer chest pains (VOA, 2013).

\subsection{Application of Preventive Measures against Carbon Monoxide Poisoning}

Prevention of carbon monoxide (CO) poisoning has been considered a priority for preventive action for many years, as it is one of the main causes of unintentional poisoning in Europeand other countries all over the world, often resulting in permanent neurological damage or death. According to WHO (2004) strategies for prevention include: (1) Primary prevention: legal control or regulation to reduce the hazards and education to reduce behavior associated with risk. (2) Secondary prevention: reduction of the severity of carbon monoxide poisoning through early detection, early recognition of the first symptoms and early treatment. (3) Tertiary prevention: the recurrence of intoxication in the same patient or the same family can be prevented by removing the hazard from the home or workplace and changing the behaviour associated with risk; also by giving information to victims during their hospital stay and at home to enable them take measures to reduce the hazard.

According to Tremblay (2013), proper installation, operation and maintenance of combustion appliances in the home are most important in reducing the risk of $\mathrm{CO}$ poisoning. 
Never ignore symptoms, particularly if more than one person is feeling them. You could lose consciousness and die if you do nothing.

\subsection{Use of Generator Sets by Nigerians}

According to the African review of business and technology (ARBT, 2015) citing PowerGen statistics, in 2014 Nigerians imported a total of 28,678 generator units totaling to US $\$ 185.5 \mathrm{mn}$ and this can be associated with the epileptic electricity situation in Nigeria. The power crisis, coupled with high economic growth in the country, is the main factor driving growth in the generator market.

Meanwhile, importation of generator sets in Nigeria is forecast to see growth rates of 8.7 per cent driving up market volume from US\$450mn in 2011 to reach US\$950.7mn by 2020 , global research firm GBI Research indicates. Aman Madhok, energy analyst at GBI Research, said, "Sustained growth is driven by increasing electricity consumption, which has been growing at eight per cent per annum over recent years, and the inability of the Power Holding Company of Nigeria (PHCN) to supply adequate power to meet demand" cited by (ARBT,2015).

At 5,500 MW, the installed capacity of Nigeria's public electricity grid is at best $30 \%$ of current requirements, and on average most homes have access to public electricity supply for 6 hours daily. Dealing with electricity supply shortfalls for most Nigerians means procurement and installation of private diesel-powered generators. Current estimates indicate that over $90 \%$ of businesses and $30 \%$ of homes have diesel-powered generators, meaning that there are currently about 15 million generators in use in Africa's most populous nation (Awofeso, 2011).

In Nigeria, diesel / fuel emissions from domestic generators surpass those from workplaces, trucks, and buses, and pose greater risks to human health and the environment due to proximity to homes and prolonged duration of use.

\section{METHOD}

This study was designed as a survey because the topic understudy requires the respondents to express their opinions, interests and attitudes. Undergraduate students of public universities in the five (5) states that make up the South-eastern geo-political zone of Nigeria were selected as the study population.Using the multi-stage sampling technique, Imo and Anambra states were randomly selected out of the five states that make up the south eastern region. From the pool of universities in the 2 states, the researcher further randomly picked two universities each from each state. They were Imo State University Owerri, Federal University of Technology Owerri, Nnamdi Azikiwe University Awka and Chukwuemeka Odumegwu Ojukwu University (Uli /Igbariam campuses). Two faculties were then randomly picked from each university, after which two levels of study from eight departments - one department from each of the eight pre-selected faculties from the four universities - were again randomly picked. A sample of 398 students was arrived at using the Philip Meyer's published table and Taro Yamane's formula for determining sample size $n=N / 1+N(e)^{2}$. However, a sample of 400 was decided on to allow a 5 per cent error tolerance. A validated 42-item questionnaire was used as the data collection instrument. Questions were asked to get respondents' answers on their exposure to label warning messages and their knowledge about carbon monoxide gas and its preventive measures.

\section{RESULTS}

394 of the total 400 copies of the questionnaire distributed were returned. This represents 98.5 percent of the sample of 400 respondents. Against the backdrop of Myer's sample of 384, and the calculated sample of 399, using Taro Yamane's formula; plus, the suggestions of Stack and Hockings (1999:217) and Nwuneli (1991:11), this response rate had been considered appreciable enough to provide the necessary data for this study; hence its use.

Data derived from the questionnaire show that 51 percent $(\mathrm{N}=199)$ of the 394 respondents were female, 48 percent $(\mathrm{N}=190)$ were male and 1 percent was missing. It also showed that 289 respondents were between the ages of 18 and 22, 99 of them fell in the 23-27 age bracket, 7 were between 28 and 32 years old, and 3 respondents were 33 years old and above. This suggests that respondents within the age bracket of 18-22 years constitute the highest populated sampled. As such, they can be said to represent the actual age group of students who attends tertiary institutions in the Eastern part of Nigeria. Data collected further showed that students in 100, 200 and 300 levels made up the highest populated sample with a total of $75 \%$ while 400 and 500 levels accounted for 19\% and 6\% respectively. 


\subsection{RESPONDENTS' ACCESS TO STEADY POWER SUPPLY}

Here, the goal was to assess respondent's access to steady power supply since research has shown that the rise in purchase of power generating sets is due to the epileptic situation of power supply in Nigeria.

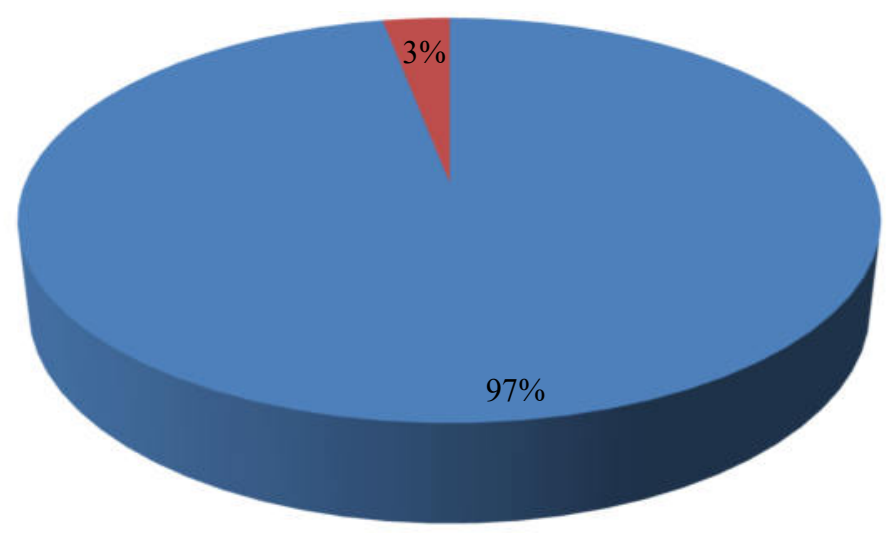

No

Yes

Figure. 4: Respondents access to steady power supply

Data in Fig 4 show that majority of the respondent (97 percent, $\mathrm{N}=382$ ) do not have access to steady power supply. While, 3 percent $(\mathrm{N}=12)$ have access to steady power supply.

\section{2.: RESPONDENTS' ACCESS TO PORTABLE GENERATOR SETS}

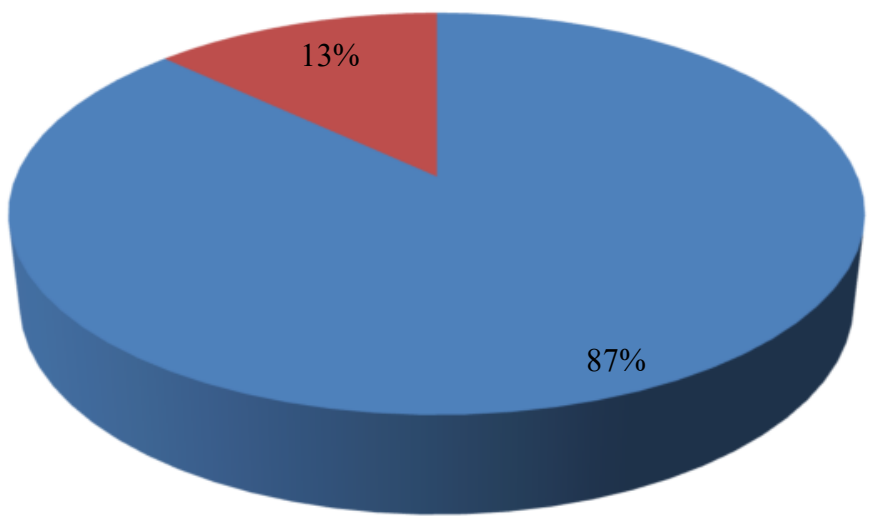

- Yes

no

Figure. 5: Respondents' access to portable generators.

Data in figure 5 show that 87 percent $(\mathrm{N}=343)$ of the respondents have access to portable generator set while 13 percent $(\mathrm{N}=51)$ of the respondents do not have access to generator sets. This shows that the use of generator is on the high side and could be linked to Fig 4 above which shows that majority of the students do not have steady power supply, and therefore go for an alternative option. 


\section{3: RESPONDENTS' PLACE OF LIVING}

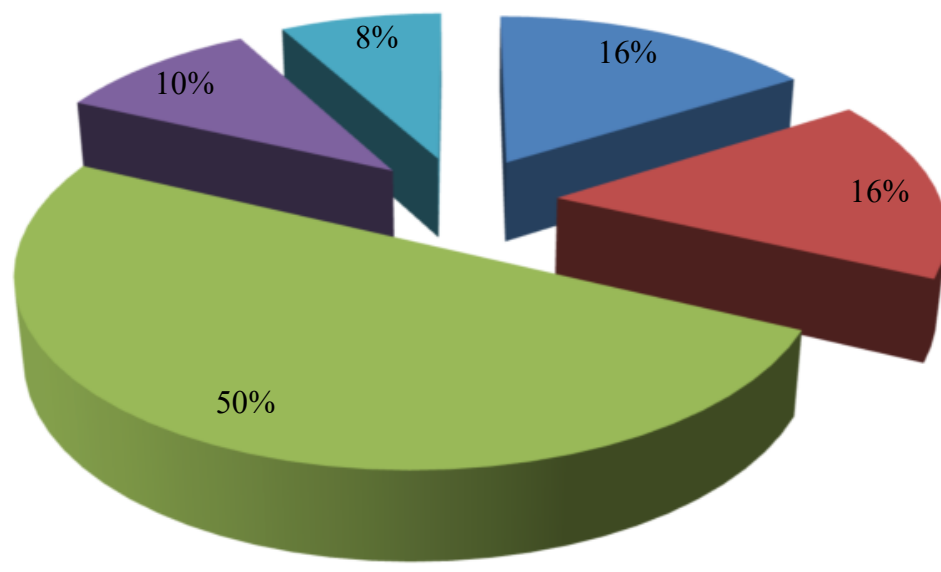

- Flat,upstairs

Face to face

Self contained

- Single room

- Others

Figure. 6: Respondents place of abode

Results in figure 6 show that 50 percent $(\mathrm{N}=198)$ of the respondents live in self-contained apartments, 16 percent $(\mathrm{N}=62)$ either live in face to face apartments or flats, upstairs while 10 percent of them live in single rooms. Obtained results therefore represent that university students in south-east Nigeria live in self-contained apartments.

\section{4: RESPONDENTS’ PLACEMENT OF THEIR PORTABL GENERATOR SET}

Here, we aimed to determine placement of their power generator sets while using it. Data collected show that a high number of the respondents do not run their portable generators far from their windows and doors just as the label warnings had stated. Therefore they may be unknowingly subjected to carbon monoxide gas.

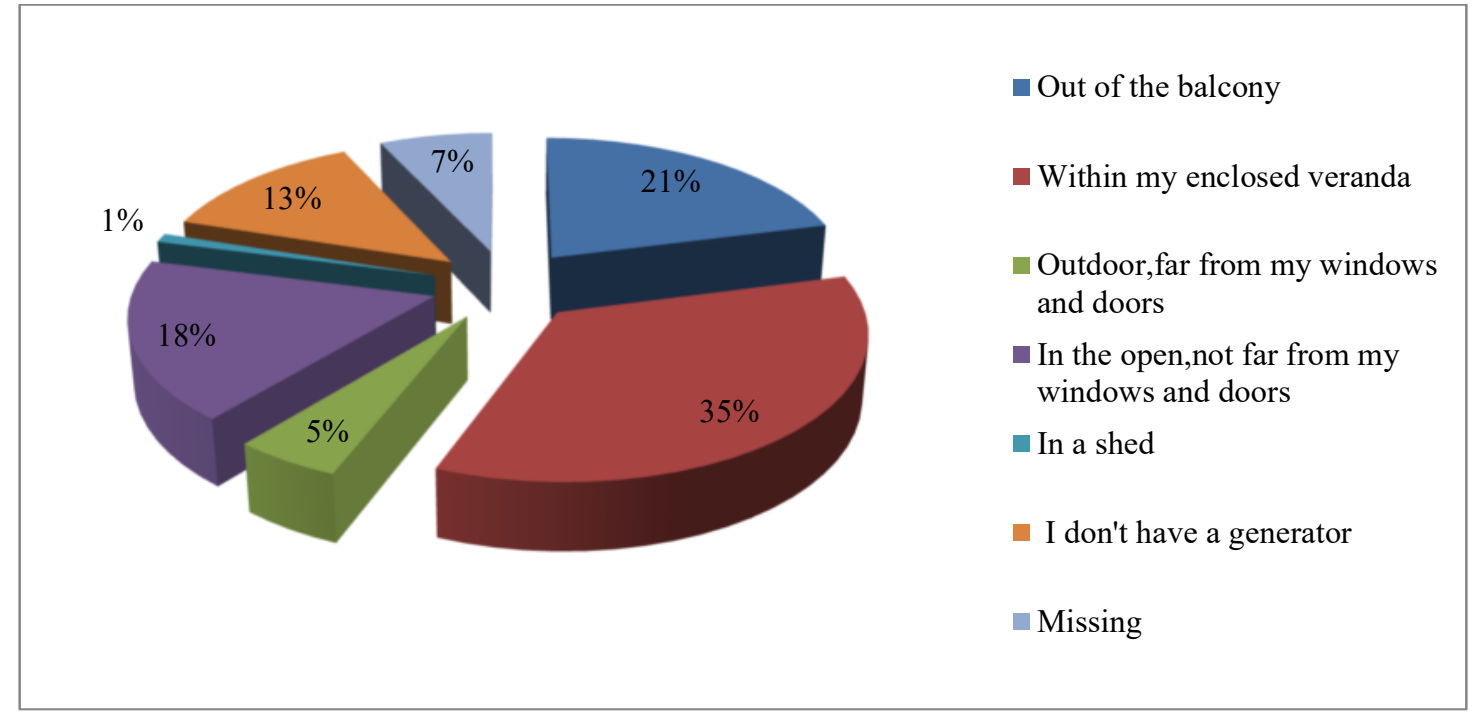

Figure. 7: Placement of portable generators 
Data in figure 7 show that more than a quarter of the respondents ( 35 percent, $\mathrm{N}=134$ ) run their generators within their enclosed verandas, 21 percent $(\mathrm{N}=82)$ run their generators out of their balconies, 18 percent $(\mathrm{N}=78)$ run it in the open not far from their windows and doors while only 5 percent $(\mathrm{N}=17)$ operate their generators outdoors, far from their windows and doors.

\section{5:RESPONDENT'S AWARENESS OF LABELS WARNINGS ON HOUSEHOLD PRODUCTS}

Table 1:Respondent's Awareness of Labels Warnings on Household Products

\begin{tabular}{|c|r|r|}
\hline Variables & Frequency & \multicolumn{1}{|c|}{ Percentage } \\
\hline No & 82 & $21 \%$ \\
Yes & 312 & $79 \%$ \\
Total & 394 & $100 \%$ \\
\hline
\end{tabular}

The analysis in Table 1 shows that $79 \%$ of the total respondents are aware that household products which are likely to hurt or harm them contain danger/warning labels while $21 \%$ of the respondents are unaware. This therefore indicates that respondents are aware and exposed to label warnings on different house hold products that can endanger one's life if not properly and carefully handled/used.

\section{6: RESPONDENTS' FREQUENCY OF EXPOSURE TO LABEL WARNINGS ON HOUSEHOLD PRODUCTS}

Table 2: Respondents' Frequency of Exposure to Label Warnings on Household Products

\begin{tabular}{|c|c|c|}
\hline Variables & Frequency & Percentage \\
\hline $\begin{array}{l}\text { Very Often } \\
\text { Not Often } \\
\text { Not at All } \\
\text { Missing } \\
\text { Total }\end{array}$ & $\begin{array}{r}30 \\
282 \\
73 \\
9 \\
394\end{array}$ & $\begin{array}{r}8 \% \\
73 \% \\
19 \% \\
2 \% \\
100 \%\end{array}$ \\
\hline
\end{tabular}

In the Table above, the attempt was made to establish respondent's frequency to the exposure of label warnings on house hold product. A large number of the respondents comprising of $73 \%(\mathrm{~N}=282)$ of the total population sampled said that they do not regularly expose themselves to these messages, $30 \%$ said that they often expose themselves to these messages, $19 \%$ stated that they do not expose themselves to these messages at all while $2 \%$ did not answer the question. This shows that though a large number of the respondents are aware of label warning on household product, a good number of them do not frequently expose themselves to these messages which are intended to keep them from harm.

\section{7: RESPONDENTS' AWARENESS OF PORTABLE GENERATOR LABEL WARNINGS}

Table 3: Respondents' Awareness of Portable Generator Label Warnings

\begin{tabular}{|l|r|r|}
\hline \multicolumn{1}{|c|}{ Variables } & Frequency & \multicolumn{1}{|c|}{ Percentage } \\
\hline No & & 238 \\
Yes & 93 & $60 \%$ \\
I don't have a generator & 63 & $24 \%$ \\
Total & 394 & $16 \%$ \\
\hline
\end{tabular}


The warning message inscriptions on portable generator sets (I Better Pass My Neighbour) are very tiny and not easily seen. An attempt was therefore made to establish respondents' awarenessof these label warnings on their portable generator sets. Majority $(60 \%(\mathrm{~N}=238)$ of the respondents are unaware that there is a label warning message on their portable generator set. This suggests that though the manufacturers of portable generator sets have deemed it necessary to inform its customers on the proper way to use and maintain their generator sets in order to avoid any health hazard or injury, a large proportion of the population sampled are stillunaware that these messages exist on generators.

\section{8: RESPONDENTS' COMPREHENSIBILTY OF THE WARNING MESSAGE ON PORTABLE GENERATOR}

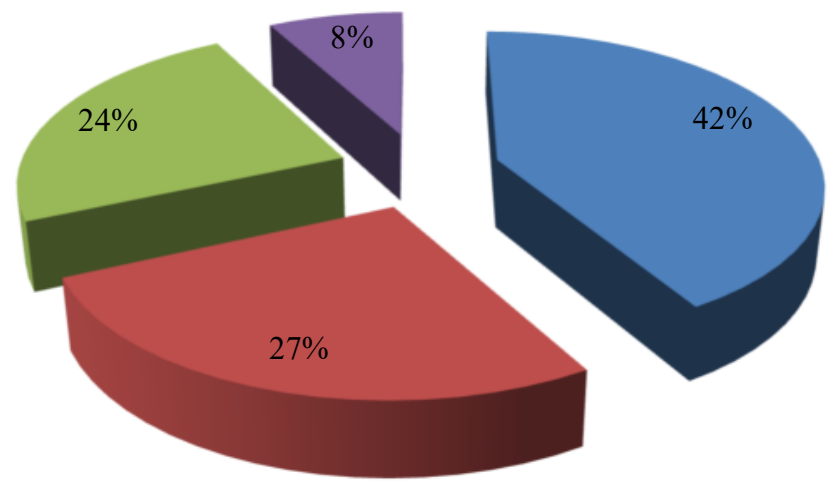

No

- Yes

I don't know

- Missing

Figure. 8: Respondents who comprehend label warnings.

Findings in figure 8 show that $42 \%(\mathrm{~N}=167)$ of the respondents did not understand the message communicated through the label warning on their portable generators, $24 \%(\mathrm{~N}=101)$ didn't know whether or not they understood it, $27 \%(\mathrm{~N}=95)$ indicated that they understood the message, and $8 \%(\mathrm{~N}=31)$ did not answer the question thereby falling under the missing section. This result shows that the intended aim of the communicated message was not achieved with majority of the respondents.

\section{9: RESPONDENTS' ATTITUDE TOWARDS THE LABEL WARNING}

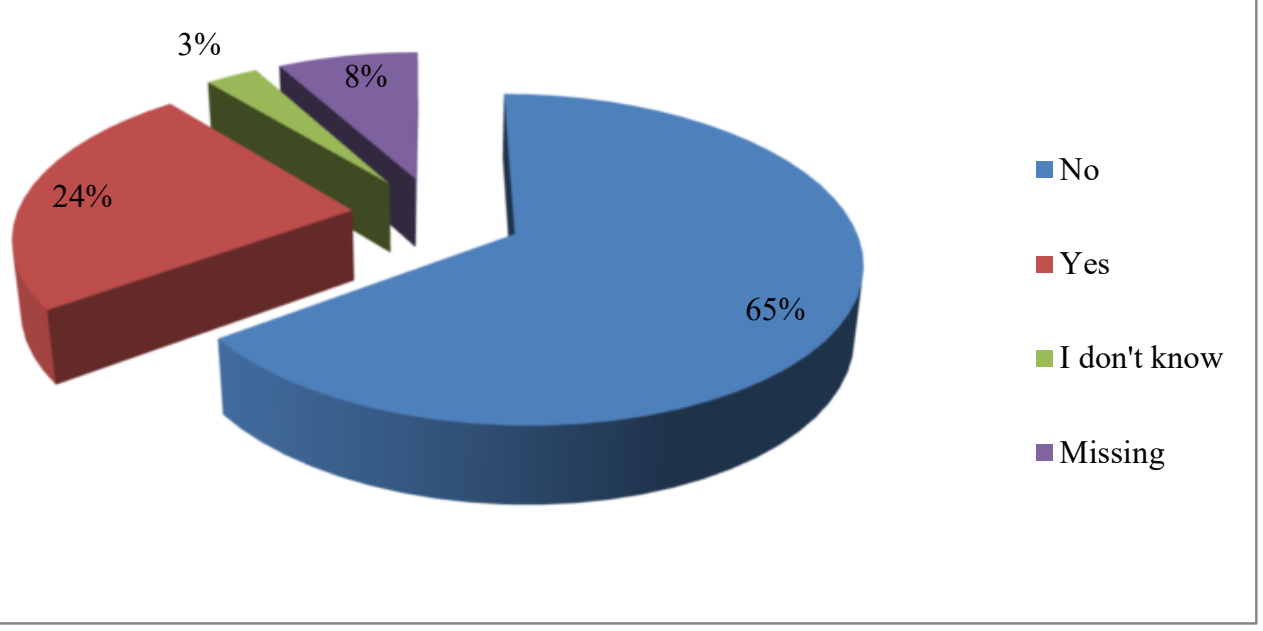

Figure. 9: Respondents' attitude towards the label warning 
A question was posed to find out if the respondents followed the instructions that were written on the label warnings of their portable generator set. Data suggests that out of the 394 questionnaire which were returned, $65 \%$ $(\mathrm{N}=256)$ of the respondents did not follow the instructions, $24 \%(\mathrm{~N}=96)$ followed the instructions, $3 \%(\mathrm{~N}=11)$ answered "I don't know", while $8 \%(\mathrm{~N}=31)$ was missing.

\subsection{0: RESPONDENTS'AWARENESS OF CARBON MONOXIDE}

Table 4: Respondents' Awareness of Carbon Monoxide

\begin{tabular}{|c|r|r|}
\hline Variables & Frequency & Percentage \\
\hline No & 31 & $8 \%$ \\
Yes & 363 & $92 \%$ \\
Total & 394 & $100 \%$ \\
\hline
\end{tabular}

The table above reveals that a good percentage of the respondents are aware of Carbon monoxide. Details show that $92 \%$ of the respondents scored high on the awareness of CO index while only $8 \%$ of the sampled respondents weren't aware of CO.

The different sources of information pertaining carbon monoxide were analyzed in Table 5 .

\subsection{1: RESPONDENTS' ACCESS TO CARBON MONOXIDE INFORMATION}

Table 5: Respondents' Access to Carbon Monoxide Information

\begin{tabular}{|l|r|r|}
\hline \multicolumn{1}{|c|}{ Variables } & Frequency & \multicolumn{1}{|c|}{ Percentage } \\
\hline & & \\
Media & 61 & $16 \%$ \\
Read about it & 139 & $35 \%$ \\
Friends and Family & 164 & $42 \%$ \\
Haven't heard about it & 13 & $3 \%$ \\
Missing & 17 & $4 \%$ \\
Total & 394 & $100 \%$ \\
\hline
\end{tabular}

The different sources of information pertaining carbon monoxide were analysed in Table 5 . Result shows that $35 \%$ of the respondents deliberately exposed themselves to the information on carbon monoxide through reading. $42 \%$ of the respondents heard about it through family and friends while the media being a source of information scored low with $16 \%$ out of the total. $3 \%$ of the respondents haven't heard about it and $4 \%$ of the respondent did not answer the question. This therefore suggests that the media is not playing an active role to inform the public of the menace associated with carbon monoxide.

\subsection{2: RESPONDENTS' KNOWLEDGE OF THE CHARACTERISTICS AND SOURCES OF CARBON MONOXIDE}

Table 6: Respondents' Knowledge of the Characteristics and Sources of Carbon Monoxide

\begin{tabular}{|l|l|l|}
\hline Response & Carbon monoxide is poison you cannot see or smell & Sources of Carbon Monoxide \\
\hline False & $42 \%(\mathrm{~N}=167)$ & $7 \%(\mathrm{~N}=26)$ \\
\hline True & $33 \%(\mathrm{~N}=130)$ & $65 \%(\mathrm{~N}=254)$ \\
\hline I don't Know & $25 \%(\mathrm{~N}=97)$ & $30 \%(\mathrm{~N}=112)$ \\
\hline Total & $100 \%(\mathrm{~N}=394)$ & $100 \%(\mathrm{~N}=394)$ \\
\hline
\end{tabular}


Data collected revealed that majority of the respondents are not aware and knowledgeable about the different characteristics of carbon monoxide. Respondents were asked their take on whether "Carbon monoxide is poison you cannot see or smell". 42 percent of them answered false and 25\% did not know if carbon monoxide is poison that cannot be seen or perceived. Although a higher number of the respondents either answered false or I don't know, 33 percent of the respondents agreed that carbon monoxide is a poison that cannot be seen or perceived. This result shows that although respondents are aware of carbon monoxide, they are not fully informed about the features and dangers of the gas.

The data in Table7 also revealed that more than half of the respondents are aware of the different sources which emit the carbon monoxide gas. 65 percent of these respondents agreed that carbon monoxide can be emitted through; kerosene stoves, kerosene lanterns, gas cookers, wood stoves, portable petrol or diesel electricity generators, petrol or diesel cars and trucks, airplanes, motorboats, motorcycles, petrol-powered lawn equipment, coal pots, bush burning etc. 7 percent did not agree that all the sources listed above emit carbon monoxide gas while 20 percent did not know if the sources listed emit the gas or not.

\subsection{3: RESPONDENTS' PROPER USAGE OF PORTABLE GENERATORS}

\section{Table 7: Respondents' Proper Usage of Portable Generators}

\begin{tabular}{|l|l|l|l|}
\hline Variables & $\begin{array}{l}\text { Portable generators } \\
\text { used in confined } \\
\text { spaces can produce } \\
\text { high levels of CO }\end{array}$ & $\begin{array}{l}\text { Using portable } \\
\text { generators inside a } \\
\text { home even when } \\
\text { doors are open makes } \\
\text { you subject to CO } \\
\text { poisoning }\end{array}$ & $\begin{array}{l}\text { Using portable } \\
\text { generators indoors } \\
\text { can kill you in } \\
\text { minutes. }\end{array}$ \\
\hline False & $25 \%(\mathrm{~N}=99)$ & $9 \%(\mathrm{~N}=36)$ & $13 \%(\mathrm{~N}=51)$ \\
\hline True & $38 \%(\mathrm{~N}=149)$ & $67 \%(\mathrm{~N}=263)$ & $40 \%(\mathrm{~N}=159)$ \\
\hline I don't know & $37 \%(\mathrm{~N}=146)$ & $23 \%(\mathrm{~N}=90)$ & $48 \%(\mathrm{~N}=184)$ \\
\hline Missing & 0 & $100 \%(\mathrm{~N}=5)$ & $100 \%(\mathrm{~N}=394)$ \\
\hline Total & $100 \%(\mathrm{~N}=394 \%)$ & $100 \%(\mathrm{~N}=394)$ & \\
\hline
\end{tabular}

From the above, inquisition was aimed at determining if respondents are knowledgeable as to the universally accepted usage and placement of generators in homes. A high number of the sampled population (38\%) agreed that using portable generators in confined spaces can result to a high level of CO, a nearly equal number $(37 \%)$ did not know, and 25 percent of the respondents did not agree that the level of CO can increase when used in confined spaces.

Further questions were asked. In line with answers, more than half of the respondents (67 percent) agreed that it was not proper to use generators indoors, almost quarter of the respondents ( 23 percent) didn't know if it was proper or not to use their portable generators indoors, while 9 percent of the respondents did not agree that using generators indoors can subject one to $\mathrm{CO}$ poisoning. Only 1 percent of the respondent did not attempt to answer the question, therefore was termed missing. In addition, 48 percent of the respondents did not know that using generators indoors can kill them in minutes while 40 percent of the respondents were aware that it can. Only 13 percent of the respondents did not agree that using the machine indoor can kill in minutes. 
This result shows that although respondents are aware that carbon monoxide is a very deadly gas, majority of them do not know the proper ways to place or use their portable generators. This could be linked to the findings on level of comprehension of label warnings, which showed that a high number of the respondents did not understand the message, therefore could not follow the instructions written on it.

\subsection{4: RESPONDENTS'AWARENESS OF THE SYMPTOMS OF CARBON MONOXIDE}

The symptoms of exposure to carbon monoxide (CO) can be similar to those of many other conditions, such as food poisoning and flu. The focal point here was to determine if respondents could recognize and distinguish the different symptoms when exposed to carbon monoxide gas.

Table 8: Respondents' Awareness of the Symptoms of Carbon Monoxide

\begin{tabular}{|c|c|c|c|c|c|}
\hline Symptoms & & Varia & les & & \\
\hline & False & True & I don't Know & Missing & Total \\
\hline Chest pains & $38 \%(\mathrm{~N}=148)$ & $31 \%(\mathrm{~N}=123)$ & $31 \%(\mathrm{~N}=123)$ & 0 & $100 \%(\mathrm{~N}=394)$ \\
\hline Dizziness & $33 \%(\mathrm{~N}=128)$ & $24 \%(\mathrm{~N}=93)$ & $44 \%(\mathrm{~N}=173)$ & 0 & $100 \%(\mathrm{~N}=394)$ \\
\hline Palpitation & $27 \%(\mathrm{~N}=107)$ & $27 \%(\mathrm{~N}=104)$ & $44 \%(\mathrm{~N}=173)$ & $3 \%(\mathrm{~N}=10)$ & $100 \%(\mathrm{~N}=394)$ \\
\hline Nausea & $27 \%(\mathrm{~N}=107)$ & $27 \%(\mathrm{~N}=104)$ & $44 \%(\mathrm{~N}=173)$ & $3 \%(\mathrm{~N}=10)$ & $100 \%(\mathrm{~N}=394)$ \\
\hline Vomiting & $38 \%(\mathrm{~N}=148)$ & $31 \%(\mathrm{~N}=123)$ & $31 \%(\mathrm{~N}=123)$ & 0 & $100 \%(\mathrm{~N}=394)$ \\
\hline Stomach Pains & $40 \%(\mathrm{~N}=158)$ & $29 \%(\mathrm{~N}=113)$ & $31 \%(\mathrm{~N}=123)$ & 0 & $100 \%(\mathrm{~N}=394)$ \\
\hline Headache & $32 \%(\mathrm{~N}=127)$ & $37 \%(\mathrm{~N}=144)$ & $31 \%(\mathrm{~N}=123)$ & 0 & $100 \%(\mathrm{~N}=394)$ \\
\hline Drowsiness & $38 \%(\mathrm{~N}=148)$ & $13 \%(\mathrm{~N}=52)$ & $39 \%(\mathrm{~N}=153)$ & $10 \%(\mathrm{~N}=41)$ & $100 \%(\mathrm{~N}=394)$ \\
\hline Disorientation & $40 \%(\mathrm{~N}=158)$ & $3 \%(\mathrm{~N}=10)$ & $44 \%(\mathrm{~N}=173)$ & $13 \%(\mathrm{~N}=52)$ & $100 \%(\mathrm{~N}=394)$ \\
\hline Fits & $40 \%(\mathrm{~N}=158)$ & $3 \%(\mathrm{~N}=10)$ & $44 \%(\mathrm{~N}=173)$ & $13 \%(\mathrm{~N}=52)$ & $100 \%(\mathrm{~N}=394)$ \\
\hline Total & $35 \%(\mathrm{~N}=1387)$ & $22 \%(\mathrm{~N}=876)$ & $\begin{array}{l}39 \% \\
N=1510)\end{array}$ & $\begin{array}{l}4 \% \\
(\mathrm{~N}=163)\end{array}$ & $\begin{array}{l}100 \% \\
(\mathrm{~N}=3936)\end{array}$ \\
\hline
\end{tabular}

Results show that majority of the respondents do not know the symptoms of carbon monoxide. The Table revealed 39 percent of the respondents do not know that the indicated symptoms are also symptoms of carbon monoxide gas, a low 22 percent answered positively as to their awareness of the symptoms listed, 35 percent of them disagreed that these symptoms are associated with the deadly gas while 4 percent did not attempt to answer the question. Following this, it is clear that respondents are not fully informed about the fast-killer gas. The reason for this could be associated with the fact that most CO symptoms are mostly mistaken for either flu or other minor illness.

\subsection{5: PREVENTION OF CARBON MONOXIDE GAS}

We sought to determine if respondents are aware of the basic measure to taketo prevent exposure to carbon monoxide. The basic preventive measure specifically referred to here is the running of generators far from their windows and doors.

Data collected and presented in the figure below suggests that over half of the respondents (62 percent $\mathrm{N}=243$ ) are aware of the basic preventive measures, 25 percent $(\mathrm{N}=100)$ of the respondents are not aware that running their portable generator set away from their windows could prevent them from being exposed to this deadly gas, and 13 percent $(\mathrm{N}=51)$ of the respondents do not own personal generators, so could not ascertain if running generators far from windows would avoid being exposed to the gas. 


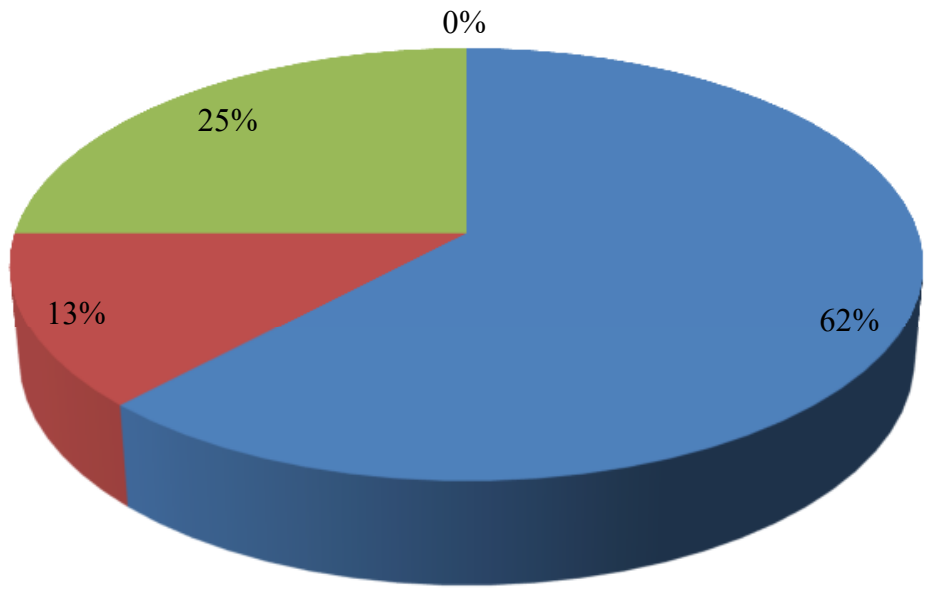

I don't have generator

I don't know

No

Figure 10: Efforts to prevent carbon monoxide among the respondents

\subsection{6: REPONDENTS' KNOWLEDGE OFTHE IMMEDIATE TREATMENT OF CARBON} MONOXIDE

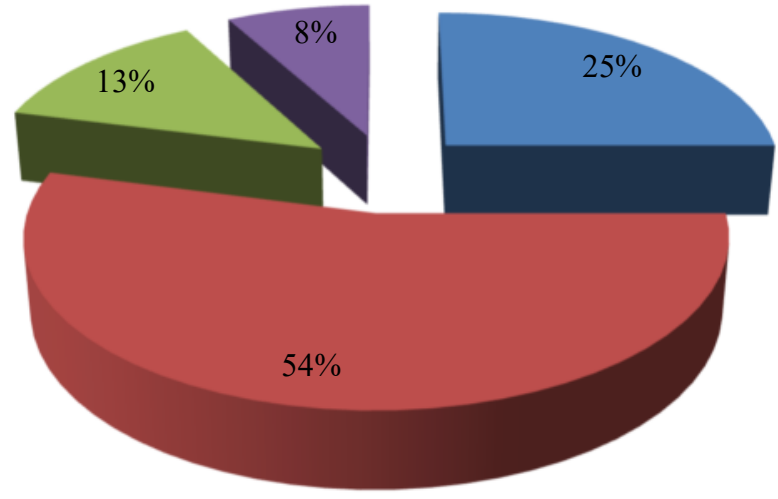

- Yes

$\square$ No

I don't have generator

I don't know

Figure 11: Respondents' knowledge of the treatment of carbon monoxide

Data presented in figure 11 above suggests that a high level of the respondents ( 54 percent $\mathrm{N}=211$ ) are not aware that getting fresh air immediately if they feel weak or dizzy while running their generators is an immediate treatment for carbon monoxide gas. One quarter of the respondents $(25$ percent $\mathrm{N}=100)$ are aware of this immediate treatment. This findings show that there is little awareness/knowledge on carbon monoxide gas. The low level of knowledge to carbon monoxide treatment might be linked to the high level of unmonitored and unintentional poisoning from the gas, therefore the need to inform the populace in very important. 


\subsection{7: RESPONDENTS' FREQUENCY OF RUNNING THEIR GENERATORS OUTSIDE}

Table 9: Respondents' Frequency of Running their Generators Outside

\begin{tabular}{|l|r|r|}
\hline & Frequency & \multicolumn{1}{|c|}{ Percentage } \\
\hline & & \\
As Often as I use it & 100 & $25 \%$ \\
Sometimes & 213 & $54 \%$ \\
I don't know & 20 & $5 \%$ \\
I don't have a generator & 51 & $13 \%$ \\
Missing & 10 & $3 \%$ \\
Total & 394 & 100,0 \\
& & \\
\hline
\end{tabular}

The aim here was to find out how often respondents make conscious effort to run their generators outside. Data collected shows that one quarter of the respondents ( 25 percent) use their generators outside as often as they use it, 54 percent run their generators outside sometimes, and 5 percent did not know if they made conscious effort to run their generators outside. This result may be related to Table 7, where a high number of the respondents run their generators within their enclosed veranda.

\subsection{8: RESPONDENTS' DIRECT CONTACT WITH CARBON MONOXIDE GAS}

Table 10: Respondents' Direct Contact with Carbon Monoxide Gas

\begin{tabular}{|l|l|l|l|l|l|l|}
\hline \multicolumn{1}{|c|}{ Variables } & \multicolumn{1}{|c|}{ Yes } & \multicolumn{1}{|c|}{ No } & $\begin{array}{l}\text { I don't } \\
\text { have a } \\
\text { generator }\end{array}$ & $\begin{array}{c}\text { I don't } \\
\text { know }\end{array}$ & Missing & Total \\
\hline $\begin{array}{l}\text { Have you ever felt } \\
\text { sick, dizzy or weak } \\
\text { while using your } \\
\text { portable generator }\end{array}$ & $\begin{array}{l}21 \% \\
(\mathrm{~N}=82)\end{array}$ & $\begin{array}{l}53 \% \\
(\mathrm{~N}=210)\end{array}$ & $\begin{array}{l}13 \% \\
(\mathrm{~N}=51)\end{array}$ & $\begin{array}{l}10 \% \\
(\mathrm{~N}=40)\end{array}$ & $\begin{array}{l}3 \% \\
(\mathrm{~N}=11)\end{array}$ & $\begin{array}{l}100 \% \\
(\mathrm{~N}=394)\end{array}$ \\
\hline $\begin{array}{l}\text { Did you, on such } \\
\text { occasions, try to get to } \\
\text { fresh air without } \\
\text { delay }\end{array}$ & $\begin{array}{l}3 \% \\
(\mathrm{~N}=10)\end{array}$ & $\begin{array}{l}10 \% \\
(\mathrm{~N}=40)\end{array}$ & & $\begin{array}{l}10 \% \\
(\mathrm{~N}=40)\end{array}$ & $\begin{array}{l}77 \% \\
(\mathrm{~N}=304)\end{array}$ & $\begin{array}{l}100 \% \\
(\mathrm{~N}=394)\end{array}$ \\
\hline
\end{tabular}

Data presented in Table 10 shows that majority of the respondents may not have had direct contact with carbon monoxide. 


\subsection{9: RESPONDENTS' AWARENESS AND KNOWLEDGE OF CARBON MONOXIDE DETECTION DEVICES}

Table 11: Respondents' Awareness and Knowledge of Carbon Monoxide Detection Devices

\begin{tabular}{|l|l|l|l|l|}
\hline Variables & Yes & No & Missing & Total \\
\hline $\begin{array}{l}\text { Do you know COA can } \\
\text { detect for possible CO }\end{array}$ & $16 \%(\mathrm{~N}=63)$ & $81 \%(\mathrm{~N}=32 \mathrm{I})$ & $3 \%(\mathrm{~N}=10)$ & $100 \%(\mathrm{~N}=394)$ \\
\hline $\begin{array}{l}\text { Do you have COA } \\
\text { installed in your } \\
\text { apartment }\end{array}$ & & $92 \%(\mathrm{~N}=362)$ & $8 \%(\mathrm{~N}=32)$ & $100 \%(\mathrm{~N}=394)$ \\
\hline $\begin{array}{l}\text { Have you seen a Smoke } \\
\text { Alarm }\end{array}$ & $61 \%(\mathrm{~N}=15)$ & $85 \%(\mathrm{~N}=333)$ & & $100 \%(\mathrm{~N}=394)$ \\
\hline $\begin{array}{l}\text { Have you seen a CO } \\
\text { Alarm }\end{array}$ & $8 \%(\mathrm{~N}=30)$ & $92 \%(\mathrm{~N}=364)$ & & $100 \%(\mathrm{~N}=394)$ \\
\hline
\end{tabular}

The purpose here was to determine if respondents are aware of devices that can be used to detect carbon monoxide gas in their homes. Findings show that majority of the respondents are not aware of carbon monoxide detection device. 81 percent are unaware that carbon monoxide alarm can help detect $\mathrm{CO}$ gas. This may be the reason why almost all the respondents ( 92 percent) do not have carbon monoxide alarm installed in their homes.

Furthermore, a high number of the respondents ( 85 percent) had never seen a smoke alarm, while 92 percent have also not seen a carbon monoxide alarm.

\section{SUMMARY AND CONCLUSION}

The main idea behind the inscription of warning messages on electric power generator sets is to inform users of the proper ways to use the machine. The main objective of this study was therefore to determine Nigerian University students' awareness of and exposure to label warnings on portable generators, their level of comprehension of the label warning messages, knowledge of carbon monoxide and if they undertake any preventive measures to avoid carbon monoxide poisoning.

Results presented were obtained from 394 undergraduate students spread across the four universities selected for the study. 51 percent of the respondents were females while 48 percent were male signifying an almost even distribution between the both sexes. More than half of the respondents ( 72 percent) were between the ages of 18 and 25 while a quarter of the respondents ( 25 percent) were between the ages of 23 and 27 years.

The study found a high level of exposure to label warnings on general household products but minimal exposure to label warnings on portable generator sets among the target populationin southeastern Nigeria. It also found that some variables like placement of the warnings, font sizes and religious inclination hindered exposure to the warnings and compliance to the warning messages. Data indicate that awareness of carbon monoxide information is high and a significant number of the respondents got informed about it either through family and friends or by reading. A poor number of them got informed through the media. The study further found that university students are aware of the carbon monoxide gas but are not properly informed of the different symptoms that are associated with it, and the preventive measures to apply when exposed to the poisonous gas. 
The overall finding of this study is that undergraduate students are not adequately exposed to label warning messages on portable generators which results to the improper use of the machine. It further found that the media is not playing an active role in informing the society of the dangers involved with carbon monoxide and generator use, even when carbon monoxide is gradually becoming a global threat. Leads were presented that should necessitate further research to establish what the scenario is like in other contexts.

\section{RECOMMENDATIONS}

Based on the findings of this study, and the findings from literature review, the following recommendations are made:

- $\quad$ Placement and font size of label warnings on small scale portable generators has been identified as factors that hinder awareness and exposure to these warnings. Manufacturers should therefore ensure to increase the font size and if possible change the placement of the warnings.

- $\quad$ As stated by C-HIP model, people are less likely to look for or read a warning for products that they do not believe are hazardous and the greater the perceived hazard, the more responsive people will be to warnings. The Medical practitioners in conjunction with media houses can properly inform the society of the importance of reading label warnings and the dangers of carbon monoxide.

- Power failure is the major reason why people settle for generators, which leads to carbon monoxide poisoning. The federal government should make great effortsto reduce this menace by providing steady power supply to the masses.

\section{References}

Akinyemi, M. L., \&Usikalu, M. R. (2013).Investigation of carbon monoxide concentration from .anthropogenic sources in Lagos, Nigeria.

Braun, C. C., Sansing, L., Kennedy, R.S., Silver, N.C. (1994). Signal word and color specifications for product warnings: an isoperformance application. In: Proceedings of the Human Factors Society 38th Annual Meeting. Human Factors and Ergonomics Society, Santa Monica, pp. 1104-1108.

Cobb, N., Etzel, R.A., 1991. Unintentional carbon monoxide related deaths in the United States, 1979 through 1988. Med. Assoc. 266, 659-663.

Council of Canadian Academics. (2015). Health Product Risk Communication: Is the Message Getting Through?

Desaulniers, D.R. (1987).Layout, organization and the effectiveness of consumer product warnings. In: Proceedings of the Human Factors Society 31st Annual Meeting. Human Factors Society, Santa Monica, CA, pp. 56-60.

Dewar, R.E. (1999). Design and evaluation of public information symbols. In: Zwaga, H.J.G., Boersma, T., Hoonhout, H.C.M. (Eds.), Visual Information for Everyday Use: Design and Research Perspectives. Taylor and Francis, London, pp. 111-117.

enHealth (Environmental Health Standing Committee). (2012). Environmental Health Risk Assessment: Guidelines for Assessing Human Health Risks from Environmental Hazards. Canberra, Australia: Australian Government Department of Health.

EMA (European Medicines Agency). (2010). The European Medicines Agency Road Map to 2015: The Agency's Contribution to Science, Medicines, Health. London, United Kingdom: EMA.

FDA (Food and Drug Administration). (2009).FDA's Strategic Plan for Risk Communication. Washington (DC): FDA.

Fischhoff, B. \& Kadvany, J. D. (2011).Risk: A Very Short Introduction. London, United Kingdom: Oxford University Press.

FMC Corporation. (1985). Product safety sign and label system. Santa Clara, CA

Frantz, J.P. (1993). Effect of location and presentation format on user processing of and compliance with product warnings and instructions.Saf. Res. 24, 131-154.

Frantz, J.P. (1994). Effect of location and procedural explicitness on user processing of and compliance with product warnings.Hum.Factors 36 (3), 532-546. 
Frantz, J.P., Miller, J.M., \& Main, B.W. (1993).The ability of two lay groups to judge product warning effectiveness. In: Proceedings of the Human Factors and Ergonomics Society Annual Meeting. Santa Monica, CA, pp. 989-993.

Frantz, J.P., \& Rhoades, T.P.(1993). A task analytic approach to the temporal placement of product warnings. Hum. Factors 35, 719- 730 .

Frantz, J.P., Rhoades, T.P., Young, S.L., \& Schiller, J.A. (2000).Assessing the effects of adding messages to warning labels. In: Proceedings of Human Factors and Ergonomics Society $41^{\text {st }}$ Annual Meeting, Vol. 4. Human Factors and Ergonomics Society, Santa Monica, CA, pp. 818-821.

Gill, R.T., Barbera, C., Precht, T. (1987).A comparative evaluation of warning label designs. In: Proceedings of Human Factors Society 31st Annual Meeting. Human Factors Society, Santa Monica, CA, pp. 476-478.

Global Business Intelligence Report (2016). Retrieved from: http://www.globalbusinessintelligence.com/

Globally Harmonized System of Classification and Labeling of Chemicals (GHS).The Issues of Comprehensibility of Label Warning. p24.

Godfrey, S.S., \& Laughery, K. R. (1993).The Biasing Effects of Product Familiarity on Consumers Awareness of Hazard.Human Factors Perspective on Warnings. California: The Human Factors and Ergonomics Society: Vol. 58-61.

Godfrey, S. S., Laughery, K.R., Young, S. L., Vaubel, K. P., Brelsford, J. W., Laughery, K. A., \& Horn, E. (1991). The new alcohol warning labels: how noticeable are they? In: Proceedings of Human Factors Society 35th Annual Meeting. Human Factors Society, Santa Monica, CA, pp. 446-45.

Hartley, J. (1994). Designing instruction text for older readers: a literature review. Br. J. Educ. Technol. 25, 172188.

Health Canada. (2006). Strategic Risk Communications Framework for Health Canada and the Public Health Agency of Canada Ottawa (ON): Health Canada and the Public Health Agency of Canada.

IRGC (International Risk Governance Council). (2008). An Introduction to the IRGC Risk Governance Framework. Geneva, Switzerland: IRGC.

Kalsher, M. J., Wogalter, M. S., \& Racicot, B.M. (1996).Pharmaceutical container labels and warnings: preference and perceived readability of alternative designs and pictorials. Int. J. Ind. Ergonomics 18, 8390.

Kline, P. B., Braun, C. C., Peterson, N., \& Silver, N. C. (1993).The impact of color on warning research. In: Proceedings of the Human Factors and Ergonomics Society 37th Annual Meeting. Human Factors and Ergonomics Society, Santa Monica, CA, pp. 940-944.

Laughery Sr., K. R., Young, S. L. (1991).An eye scan analysis of accessing product warning information. In: Proceedings of Human Factors Society 35th Annual Meeting. Human Factors Society, Santa Monica, CA, pp. 585-589.

Legal professionals.(2008). The Duty to Warn Illiterate and Non-English-Reading Product.Retrieved from http://corporate.findlaw.com/litigation-disputes/the-duty-to-warn-illiterate-and-non-english-readingproduct-users.html\#sthash.o1YAxpMM.dpuf.

Mathieu, D., Mathieu-Nolf, M., Wattel, F. (1996). Intoxication par le monoxyde de carbone: aspects actuels (Carbonmonoxidepoisoning: present aspects). Bull. Acad. Natl. Med. (Paris) 180, 965-973.

MHRA (Medicines and Healthcare Products Regulatory Agency). (2010). Communication Strategy 2010-2015. London, United Kingdom: MHRA.

Murray, L. A., Magurno, A. B., Glover, B. L., \& Wogalter, M.S. (1998). Prohibitive pictorials: evaluations of different circle-slash negation symbols. Int. J. Ind. Ergonomics 22, 473-482.

National Safety Council.(1982). How people died in home accidents, 1981. In: Accident Facts. National Safety Council, Chicago, IL, pp. 80-84.

NRC (National Research Council). (1989). Improving Risk Communication. Washington (DC): National Academy of Sciences.

Rohrmann, B. (2008). Risk Perception, Risk Attitude, Risk Communication, Risk Management: A Conceptual Appraisal. Paper presented at The International Emergency Management Society TIEMS-2008, Prague, Czech Republic.

WHO (World Health Organization). (2001). Evaluation in Health Promotion: Principles and Perspectives. Copenhagen, Denmark: Regional Office for Europe of the World Health Organization.

Wogalter, M. S., Desaulniers, D. R., Brelsford, J. W. (1987). Consumer products: how are the hazards perceived? In: Proceedings of the Human Factors Society 31st Annual Meeting. Human Factors Society, Santa Monica, CA, pp. 615-619. 
Wogalter, M. S., Godfrey, S. S., Fontenelle, G. A., Desaulniers, D.R., Rothstein,P. R., \&Laughery,K. R. (1987). Effectiveness of warnings. Hum. Factors 29 (5), 599-612.

Wogalter, M. S., Fontenelle, G. A., \& Laughery, K. R. (1985).Behavioral effectiveness of warnings. In: Proceedings of the Human Factors Society 29th Annual Meeting. Human Factors and Ergonomics Society, Santa Monica, CA, pp. 679-683.

Wogalter, M. S., Kalsher, M. J., \& Racicot, B. M. (1993). Behavioral compliance with warnings: effects of voice, context, and location. Saf. Sci. 16, 637-654.

Wogalter, M. S., \& Rashid, R. (1998).A border surround a warning sign affects looking behavior: a field observational study. In: Proceedings of the Human Factors and Ergonomics Society 42nd Annual Meeting. Human Factors and Ergonomics Society, Santa Monica, CA, p. 1628.

Wogalter, M. S., Kalsher, M. J., \& Rashid, R. (1999).Effect of signal word and source attribution on judgments of warning credibility and compliance likelihood. Int. J. Ind. Ergonomics 24, 185-192.

Wogalter, M. S., \& Shaver, E. (2001).Evaluation of list vs. paragraph text formaton search time for warning symptoms in a product manual. In: Bittner, A.C., et al. (Ed.), Advances in Occupational Ergonomics and Safety. IOS Press, Amsterdam, pp. 434-438.

Sanders, M. S., \&McCormick,E. J. (1993). Human Factors in Engineering and Design.(7 $7^{\text {th }}$ Ed). McGraw-Hill, New York.

Sojourner, R.J., \& Wogalter, M.S. (1998).The influence of pictorials on the comprehension and recall of pharmaceutical safety and warning information. Int. J. Cognitive Ergonomics 2, 93-106.

Task Force on Risk Management. (1999). Report to the FDA commissioner: Managing the Risks from Medical Product Use: Creating a Risk Management Framework. Rockville (MD). Food and Drug Administration.

Young, S.L, \& Wogalter, M.S. (1988).Memory of instruction manual warnings: effect of pictorial icons and conspicuous print. In: Proceedings of the Human Factors Society 32nd Annual Meeting, pp. 905-909.

Young, S. L., \& Wogalter, M. S. (1990). Comprehension and memory of instruction manual warnings: conspicuous print and pictorial icons. Hum. Factors 32, 637-649.

Young, S. L. (1991). Increasing the noticeability of warnings, effects of pictorial color, signal, icon and border. In: Proceedings of the Human Factors Society 36th Annual Meeting. Human Factors Society, Santa Monica, CA, pp. 580-584.

Young, S. L., Wogalter, M. S., Laughery Sr., K. R., Magurno, A., \& Lovvoll, D. (1995). Relative order and space allocation of message components in hazard warning signs. In: Proceedings of the Human Factors Society $39^{\text {th }}$ Annual Meeting. Human Factors and Ergonomics Society, Santa Monica, CA, pp. 969-973 